\title{
Electrochemiluminescence-Microscopy for microRNA Imaging in Single Cancer Cell Combined with Chemotherapy -Photothermal Therapy
}

Huairong Zhang, ${ }^{+}$Wanxia Gao, ${ }^{+,}$Yong Liu, ${ }^{+}$Yingnan Sun, ${ }^{+}$Yanxialei Jiang, ${ }^{\dagger}$ and Shusheng Zhang $^{*}+$

${ }^{+}$Collaborative Innovation Center of Tumor Marker Detection Technology, Equipment and DiagnosisTherapy Integration in Universities of Shandong, Shandong Province Key Laboratory of Detection Technology for Tumor Makers, School of Chemistry and Chemical Engineering, Linyi University, Linyi, 276005, China

‡Shandong Sino-Japanese Center for Collaborative Research of Carbon Nanomaterials, College of Chemistry and Chemical Engineering, Qingdao University, Qingdao, Shandong 266071, China

Optimization conditions of experiment.....

ECL images of HeLa cells

ECL intensities vs. Reactive oxygen species scavenger.

Cell viability of non-cancerous LO-2 cells ...

Flow cytometry of LO-2 cells

Confocal laser scanning microscopy images of LO-2 cells ..S7

Confocal laser scanning microscopy images of HeLa cells ..S8 
In order to obtain the best ECL image of HeLa cells, the concentration of luminol, incubation time of HeLa cells and probe were optimized. Under the same concentration of luminol, HeLa cells were incubated with Au NCs probe $\left(1 \mathrm{mg} \mathrm{mL}^{-1}\right)$ respectively for $0.5 \mathrm{~h}, 1 \mathrm{~h}, 1.5 \mathrm{~h}$ and $2 \mathrm{~h}$ in the cell incubator. Under the same conditions as incubation with Au NCs@PMA, HeLa cells were detected respectively with 0.00001 M, 0.00005 M, 0.0001 M and 0.001 M luminol. ECL measurements was performed with an MPI-E multifunctional electrochemical and chemiluminescent analytical system.
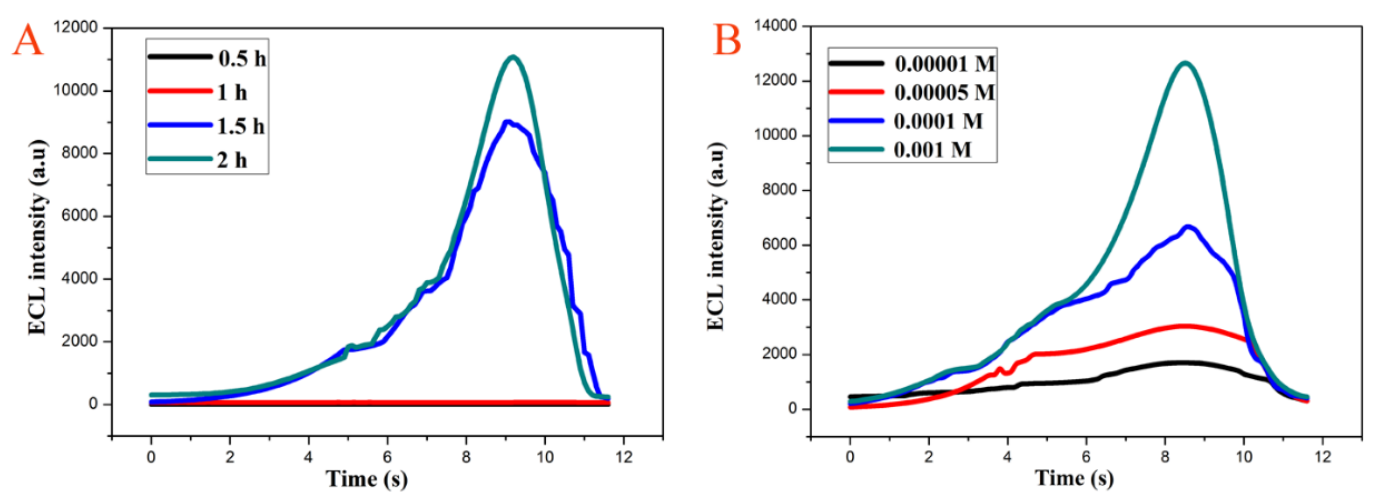

Figure S1. (A) Plot of the ECL intensities vs. incubation time with Au NCs@PMA (0.5 h - 2.5 h). (B) Plot of the ECL intensities vs. different concentration of luminol (0.00001 M-0.001 M). The detection solution $(200 \mu \mathrm{L})$ containing HeLa cells and in presence of Au NCs@PMA probes and luminol solution. The applied potential ranged from $0.8 \mathrm{~V}$ to $2.5 \mathrm{~V}$ at 100 $\mathrm{mV} \mathrm{s}^{-1}$. 
The PDMS layer was attached to the special shape of the FTO conductive electrode surface and pressed firmly. HeLa cells were incubated in FTO chip at $37^{\circ} \mathrm{C}$ for $6 \mathrm{~h}$. After HeLa cell were attached on the FTO electrode, Au NCs@PMA probe was added and cultured at $37^{\circ} \mathrm{C}$ for $2 \mathrm{~h}$. After that, $40 \mu \mathrm{L}$ luminol solution $(0.001 \mathrm{M})$ was added into detection cells. Electrochemiluminescence imaging was available by EMCCD after added $2.5 \mathrm{~V}$ voltage.

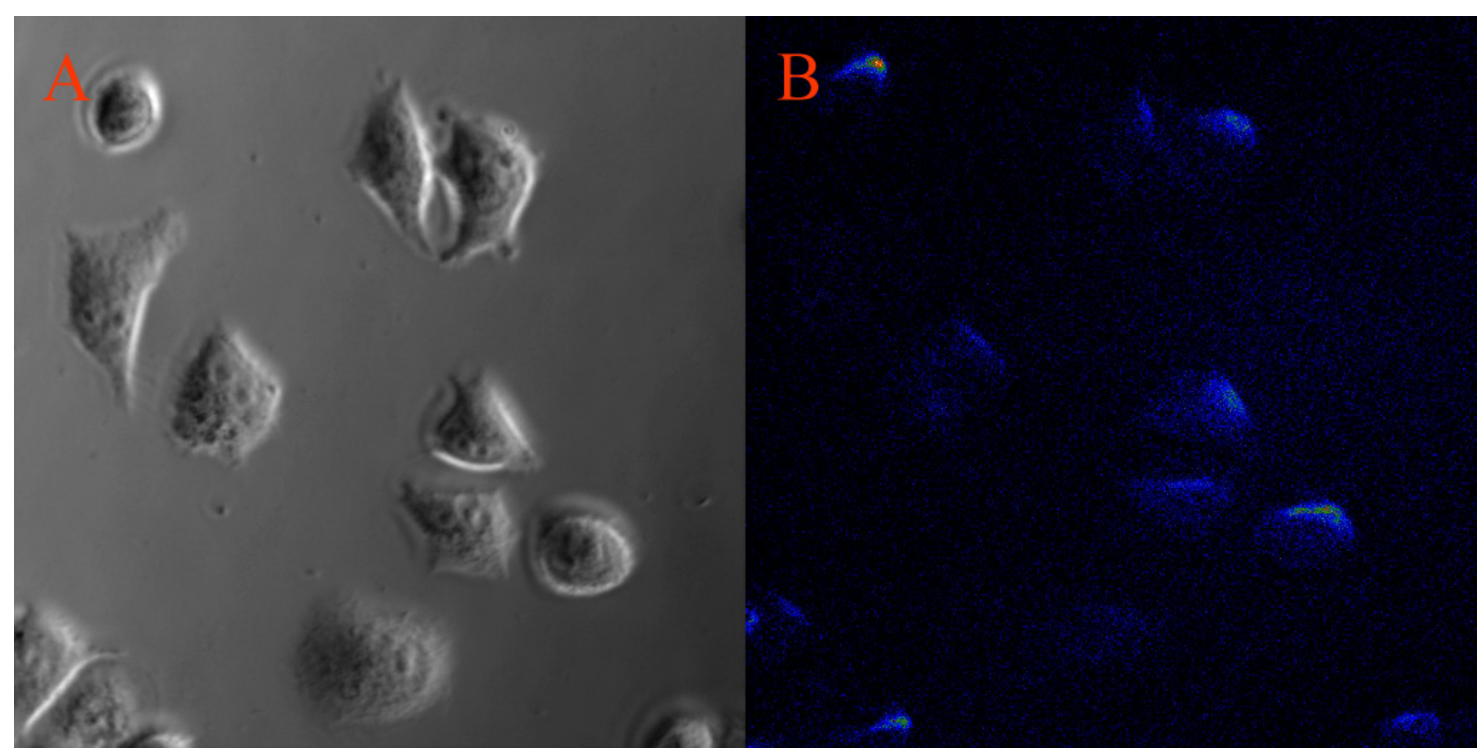

Figure S2. (A) Microscopic bright image of HeLa cells. (B) Magnified ECL images of HeLa cells on FTO chip. ECL images of cells were recorded by EMCCD by applying 2.5 V voltage, the cells were incubated with Au NCs@PMA probes. 
In order to study the effect of reactive oxygen species on ECL intensity. The reactive oxygen species scavenger NAC $(2 \mathrm{mM})$ was incubated with HeLa cells for $60 \mathrm{~min}$, then incubated with Au NCs@PMA probe for $2 \mathrm{~h}$ and reacted with $0.001 \mathrm{M}$ luminol solution. ECL measurements was performed with an MPI-E multifunctional electrochemical and chemiluminescent analytical system.

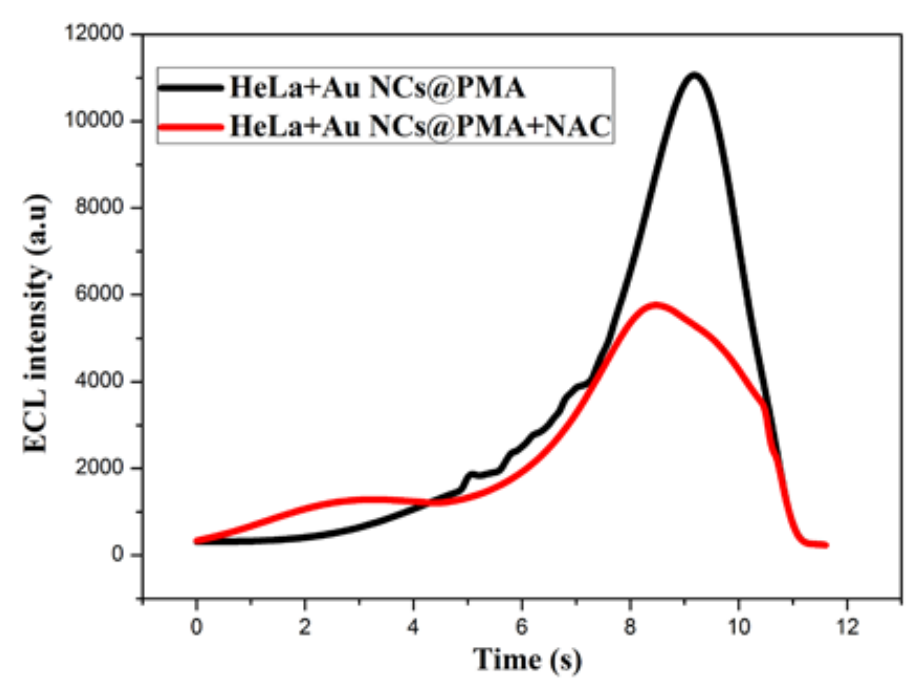

Figure S3. Plot of the ECL intensities vs. reactive oxygen species scavenger. The incubation solution $(200 \mu \mathrm{L})$ containing HeLa cells and in presence of Au NCs@PMA probes and luminol solution. The applied potential ranged from $0.8 \mathrm{~V}$ to $2.5 \mathrm{~V}$ at $100 \mathrm{mV} \mathrm{s}^{-1}$. 
LO-2 cells were incubated with Au NCs@PMA probe respectively for 2 h, 4 h, 6 h, 8 h, 12 h and 24 h in the cell incubator. CCK-8 $\left(5 \mathrm{mg} \mathrm{mL}^{-1}\right)$ was added in each well and kept at $37^{\circ} \mathrm{C}$ for $1 \mathrm{~h}$. Microplate reader was used to measure the absorbance of each well at $450 \mathrm{~nm}$. Cell viability were obtained according to the equation: Cell viability $(\%)=$ $\left(\mathrm{A}_{\text {test }} / \mathrm{A}_{\text {control }}\right)^{*} 100 \%$. The result shows Au NCs@PMA probes are harmless to LO-2 cells.

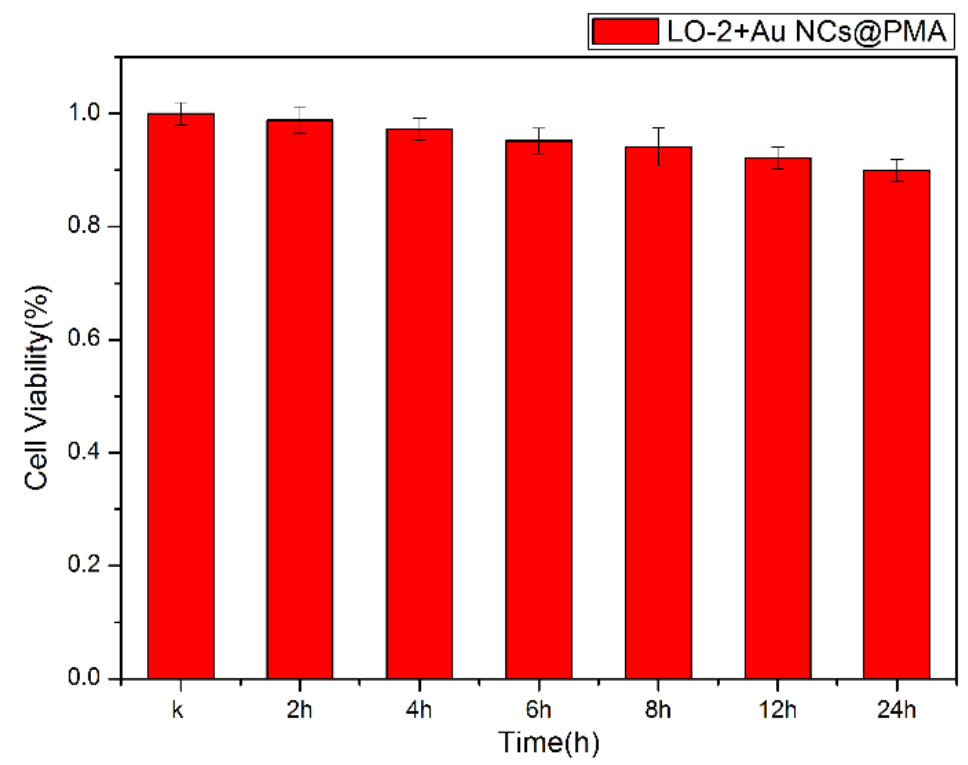

Figure S4. Cell viability of non-cancerous LO-2 cells incubated with $5 \mu \mathrm{L}$ Au NCs@PMA probe. 
LO-2 cells $\left(0.2 \mathrm{~mL}, 1 \times 10^{6}\right.$ cells mL $\left.{ }^{-1}\right)$ were incubated with Au NCs and Au NCs@PMA probe for 24 h respectively. The LO-2 cells apoptosis rates were determined by Annexin V FITC/PI Apoptosis Detection Kit and quantified by flow cytometry. Briefly, cells were harvested after incubation and stained with $5 \mu \mathrm{L}$ Annexin V-FITC for 20 min and 5 $\mu \mathrm{L}$ PI for $30 \mathrm{~min}$ with in the dark before analyzed by flow cytometry. The live cells were negative for both Annexin VFITC and PI (Annexin V-FITC ${ }^{-} / \mathrm{PI}^{-}$). Cells at the early stage of apoptosis are negative for PI but positive for Annexin V-FITC (Annexin V-FITC ${ }^{+} / \mathrm{PI}^{-}$), whereas dead cells and late-stage apoptotic cells could be stained for both PI and Annexin V-FITC (Annexin V-FITC $\left.{ }^{+} \mathrm{PI}^{+}\right)$.
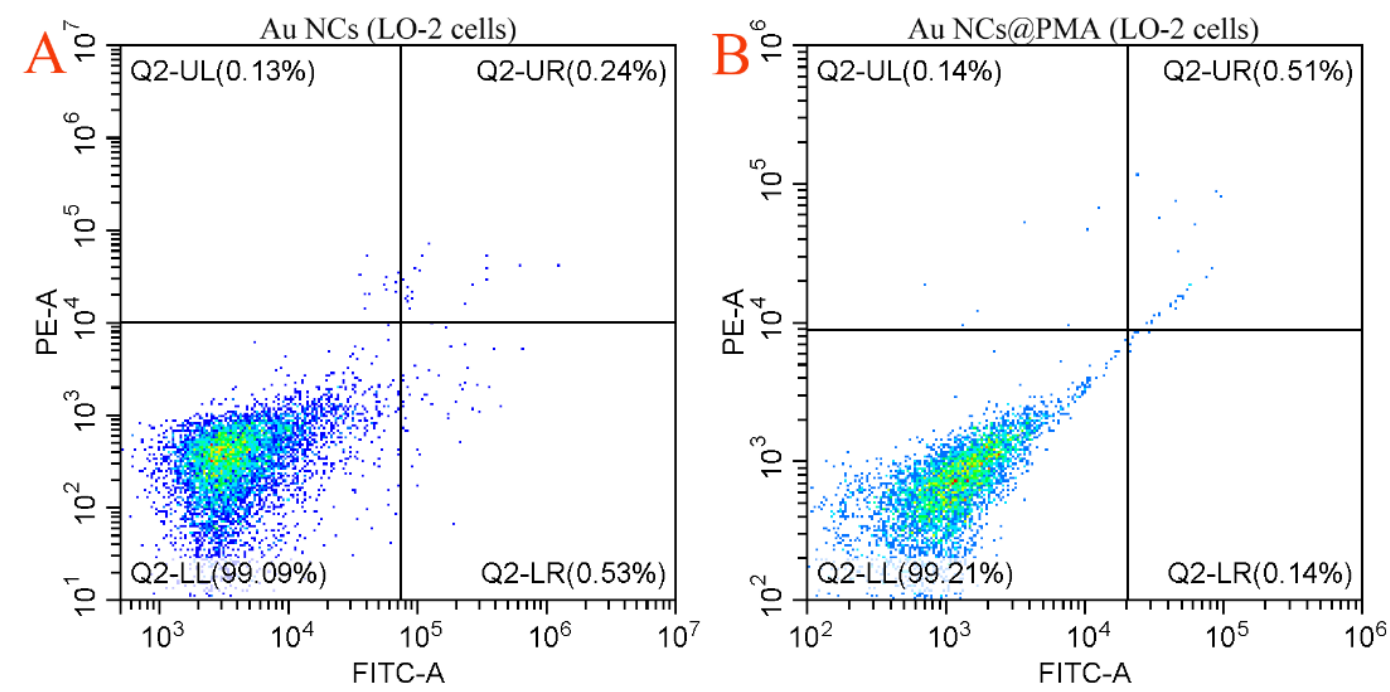

Figure S5. Flow cytometry date of LO-2 cells $\left(0.2 \mathrm{~mL}, 1 \times 10^{6}\right.$ cells $\left.\mathrm{mL}^{-1}\right)$ after incubation with Au NCs (A) and $\mathrm{Au}$ NCs@PMA probe (B) for $24 \mathrm{~h}$ and stained with Annexin V-FITC/PI Apoptosis Detection Kit. 
After LO-2 cells $\left(0.2 \mathrm{~mL}, 1 \times 10^{5}\right.$ cells $\left.\mathrm{mL}^{-1}\right)$ incubated with Au NCs@PMA probe. Cell apoptosis images were determined by Annexin V-EGFP/PI Apoptosis Detection Kit and obtained by laser confocal microscopy. Briefly, cells were harvested after incubation and stained for $15 \mathrm{~min}$ with $0.5 \mu \mathrm{L}$ Annexin V-EGFP and 20 min with $2 \mu \mathrm{L}$ PI in the dark before analyzed by confocal microscopy. The live cells were negative for both Annexin V-EGFP and PI (Annexin V-EGFP ${ }^{-} / \mathrm{PI}^{-}$). Cells at the early stage of apoptosis are negative for PI but positive for Annexin V-EGFP (Annexin V$\left.\mathrm{EGFP}^{+} / \mathrm{PI}^{-}\right)$, whereas dead cells and late-stage apoptotic cells could be stained for both PI and Annexin V-EGFP (Annexin $\left.\mathrm{V}-\mathrm{EGFP}^{+} / \mathrm{PI}^{+}\right)$.

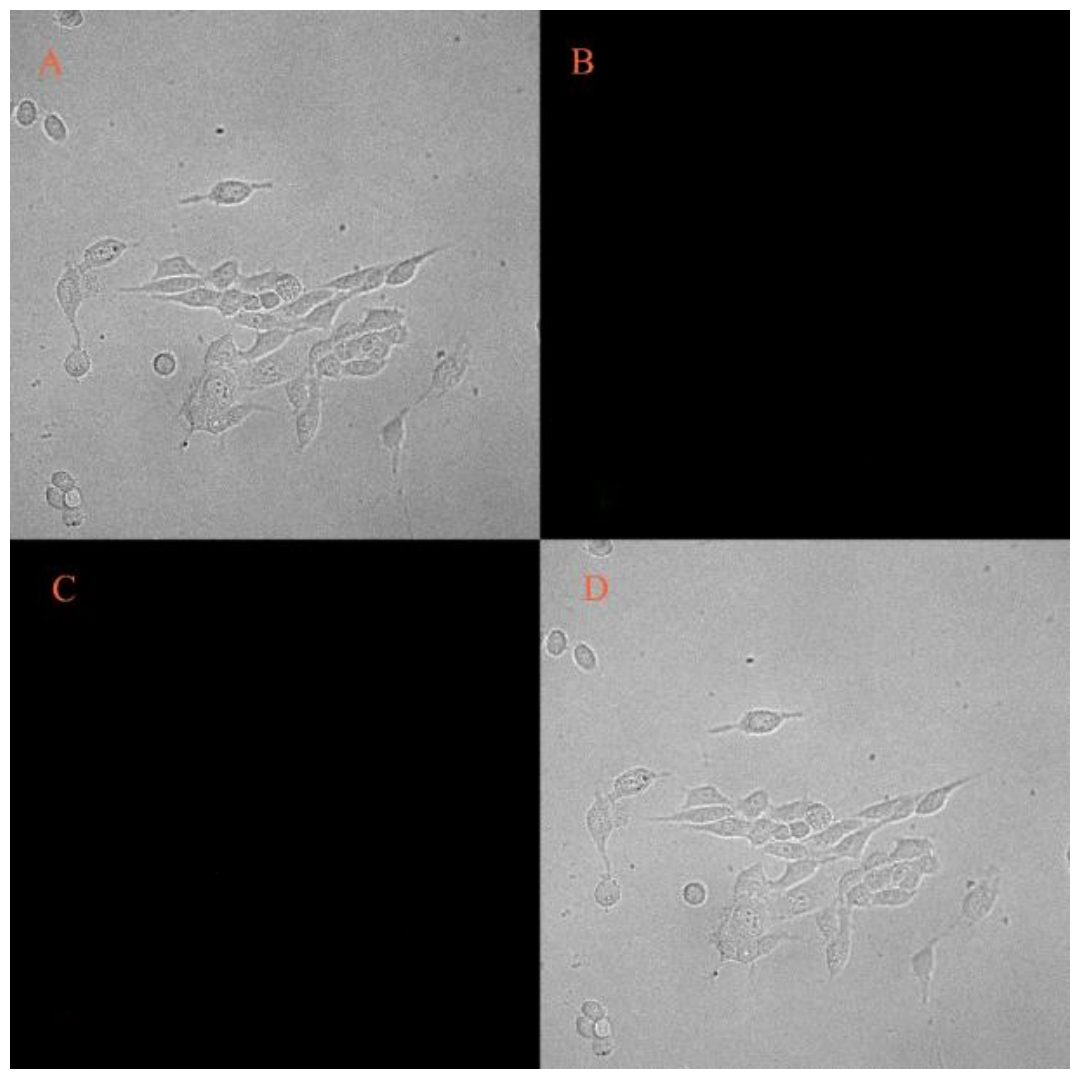

Figure S6. Confocal laser scanning microscopy (CLSM) images of LO-2 cells treated with Au NCs@PMA probe for $24 \mathrm{~h}$. (A) Bright field: provides cell information. (B) The green channel was collected at 500-570 nm under excitation at $488 \mathrm{~nm}$ to obtain the early apoptotic cells information. (Fluorescent dye, Annexin V-EGFP). (C) The red channel was collected at $650-720 \mathrm{~nm}$ under excitation at $535 \mathrm{~nm}$ to obtain the late apoptotic cells information. (Fluorescent dye, PI). (D) Merged image: green channel, red channel, and bright field. 
After HeLa cells $\left(0.2 \mathrm{~mL}, 1 \times 10^{5}\right.$ cells mL $\left.\mathrm{m}^{-1}\right)$ incubated with Au NCs@PMA probe. Cell apoptosis images were determined by Annexin V-EGFP/PI Apoptosis Detection Kit and obtained by laser confocal microscopy. Briefly, cells were harvested after incubation and stained for $15 \mathrm{~min}$ with $0.5 \mu \mathrm{L}$ Annexin V-EGFP and 20 min with $2 \mu \mathrm{L}$ PI in the dark before analyzed by confocal microscopy. The live cells were negative for both Annexin V-EGFP and PI (Annexin V-EGFP ${ }^{-} / \mathrm{PI}^{-}$). Cells at the early stage of apoptosis are negative for PI but positive for Annexin V-EGFP (Annexin V$\left.\mathrm{EGFP}^{+} / \mathrm{PI}^{-}\right)$, whereas dead cells and late-stage apoptotic cells could be stained for both PI and Annexin V-EGFP (Annexin $\left.\mathrm{V}-\mathrm{EGFP}^{+} / \mathrm{PI}^{+}\right)$.

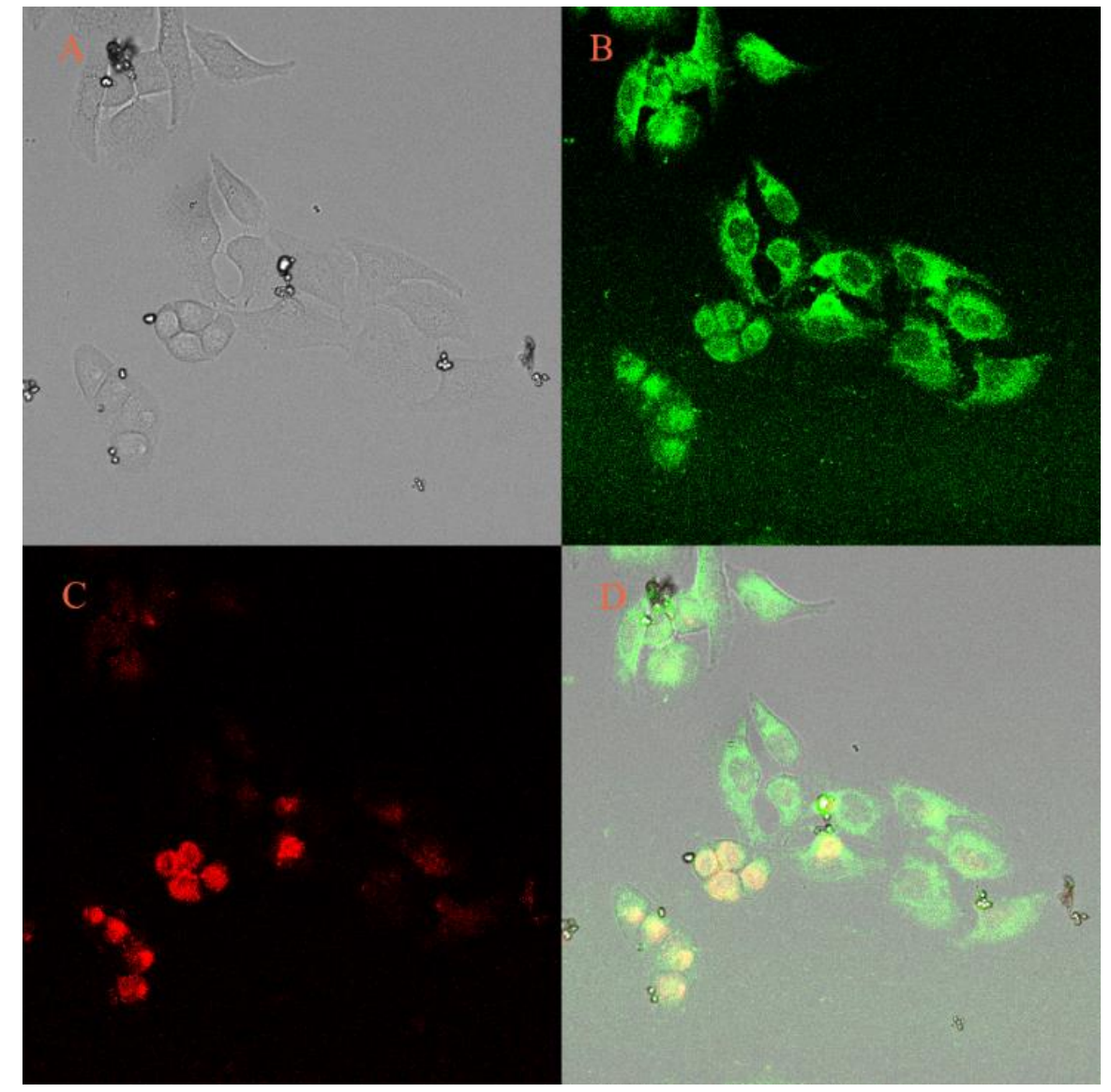

Figure S7. Confocal laser scanning microscopy (CLSM) images of HeLa cells treated with Au NCs@PMA probe for $24 \mathrm{~h}$. (A) Bright field: provides cell information. (B) The green channel was collected at 500-570 nm under excitation at $488 \mathrm{~nm}$ to obtain the early apoptotic cells information. (Fluorescent dye, Annexin V-EGFP). (C) The red channel was collected at $650-720 \mathrm{~nm}$ under excitation at $535 \mathrm{~nm}$ to obtain the late apoptotic cells information. (Fluorescent dye, PI). (D) Merged image: green channel, red channel, and bright field. 
